\title{
Intraosseous migration of second premolar below the inferior alveolar nerve canal: Case report
}

\section{Wewnątrzkostna migracja drugiego zęba przedtrzonowego poniżej kanału dolnego nerwu zębodołowego - opis przypadku}

\author{
Hamed Mortazavi ${ }^{A-F}$, Maryam Baharvand ${ }^{A-E}$, Kosar Rezaeifar ${ }^{\mathrm{F}}$ \\ Department of Oral Diseases, School of Dentistry, Shahid Beheshti University, Teheran, Iran \\ A - research concept and design; $B$ - collection and/or assembly of data; $C$ - data analysis and interpretation; \\ $D$ - writing the article; $E$ - critical revision of the article; $F$ - final approval of the article
}

Address for correspondence

Kosar Rezaeifar

E-mail: kosar.rezaeifar@gmail.com

\section{Funding sources}

None declared

Conflict of interest

None declared

Received on September 24, 2017

Reviewed on 0ctober 26, 2017

Accepted on November 27, 2017

\begin{abstract}
Migration is a kind of eruption abnormality where a tooth grows far from its original site of development. Anomalies in dental eruptions are referred to as ectopia, which might be encountered in several regions around the oral cavity. The incidence of mandibular second premolar impaction has been estimated to be $2.1-2.7 \%$. The frequency of its intraosseous distal migration is $0.25 \%$.

We report a case of extremely distally intraosseous migration of mandibular second premolar, which was found in a routine radiography. A 28-year-old woman who attended a dental clinic to treat teeth caries was noticed to have her lower second premolar located horizontally in the homolateral mandibular angle below the inferior alveolar nerve canal on a panoramic view. As the patient was asymptomatic, she was advised to take follow-up radiographs to rule out any cystic/neoplastic changes. Taking a panoramic radiograph in patients with missing mandibular premolars should be considered, because in rare cases migration or transmigration of these teeth may happen.
\end{abstract}

Key words: migration, mandible, second premolar

Słowa kluczowe: ektopia, żuchwa, drugi ząb przedtrzonowy

D0I

$10.17219 / \mathrm{dmp} / 80829$

Copyright

○ 2018 by Wroclaw Medical University

and Polish Dental Society

This is an article distributed under the terms of the

Creative Commons Attribution Non-Commercial License

(http://creativecommons.org/licenses/by-nc-nd/4.0/) 


\section{Introduction}

Anomalies in dental eruption are referred to as ectopia, which might be encountered in several regions around the oral cavity. ${ }^{1}$ When teeth are grown in areas far from their regular place of development, the condition is named migration or transmigration. ${ }^{1,2}$ According to Peck, dental migration occurs exclusively in the mandible and it refers to the horizontal movement of unerupted teeth. ${ }^{2}$ This entity occurs in permanent dentition and usually involves mandibular lateral incisors, canines, and the second premolars. There is a female predilection with a female to male ratio of $1.7: 1$. Intrabony migration of unerupted teeth may take place in both distal and mesial directions. For example, the mandibular lateral incisor and, in rare instances, the first premolar tend to migrate distally, whereas the mandibular canine most often migrates mesially and even sometimes across the midline. ${ }^{3-5}$

The prevalence of premolar impaction in the adult population is $0.5 \%$, which is reported in the range of $0.2-0.3 \%$ for mandibular premolars and $0.1-0.3 \%$ for maxillary premolars. ${ }^{5}$ On the other hand, specific articles indicate that the second mandibular premolar alone accounts for $24 \%$ of total dental impactions. ${ }^{6}$ The incidence of mandibular second premolar (MSP) impaction has been estimated to be $2.1-2.7 \%$. The frequency of its intra-osseous distal migration is $0.25 \% .{ }^{5}$ It is noted that in most instances, intrabony migration of the MSP is idiopathic, unilaterally, and without any associated dental anomalies. ${ }^{3}$ Both genetic and environmental factors are implicated in the etiology of this anomaly. Early loss of permanent first molar increases the chance of distal migration of MSP from 5\% to $10 \% .{ }^{1,7}$ Management of this condition depends on the position of the malposed tooth, the degree of discomfort, and the associated pathologic lesions, if any. ${ }^{4-7}$

In this paper, we report a 28-year-old woman with an extremely distally intrabony migration of MSP, which was found in a routine radiography.

\section{Case report}

A 28-year-old woman attended at our clinic in Tehran (Iran) to treat dental caries. She had a panoramic radiograph performed 1 week prior to her appointment. No history of systemic disease, skeletal abnormalities or dental extraction was mentioned. In the oral examination, decay of the teeth 25, 36, 46 was shown. These caries were also detected by radiography. In the clinical examination of tooth 46 , a class $\mathrm{V}$ filling on buccal side of tooth was detected. The panoramic view revealed a root canal therapy of 11 and 21, and an overhang of tooth 26. A second premolar was noticed horizontally in the homolateral mandibular angle below the inferior alveolar nerve canal (Fig. 1). The follicular space was seen as a pericoronal radiolucency with sclerotic borders around the tooth. The patient was referred to a routine exam after the discovery of the impacted teeth; because she had no symptoms, she was reluctant to attend a follow-up, and so advanced radiography (e.g., cone beam computed tomography) was not prescribed to her. The patient reported no discomfort and was not aware of this anomaly

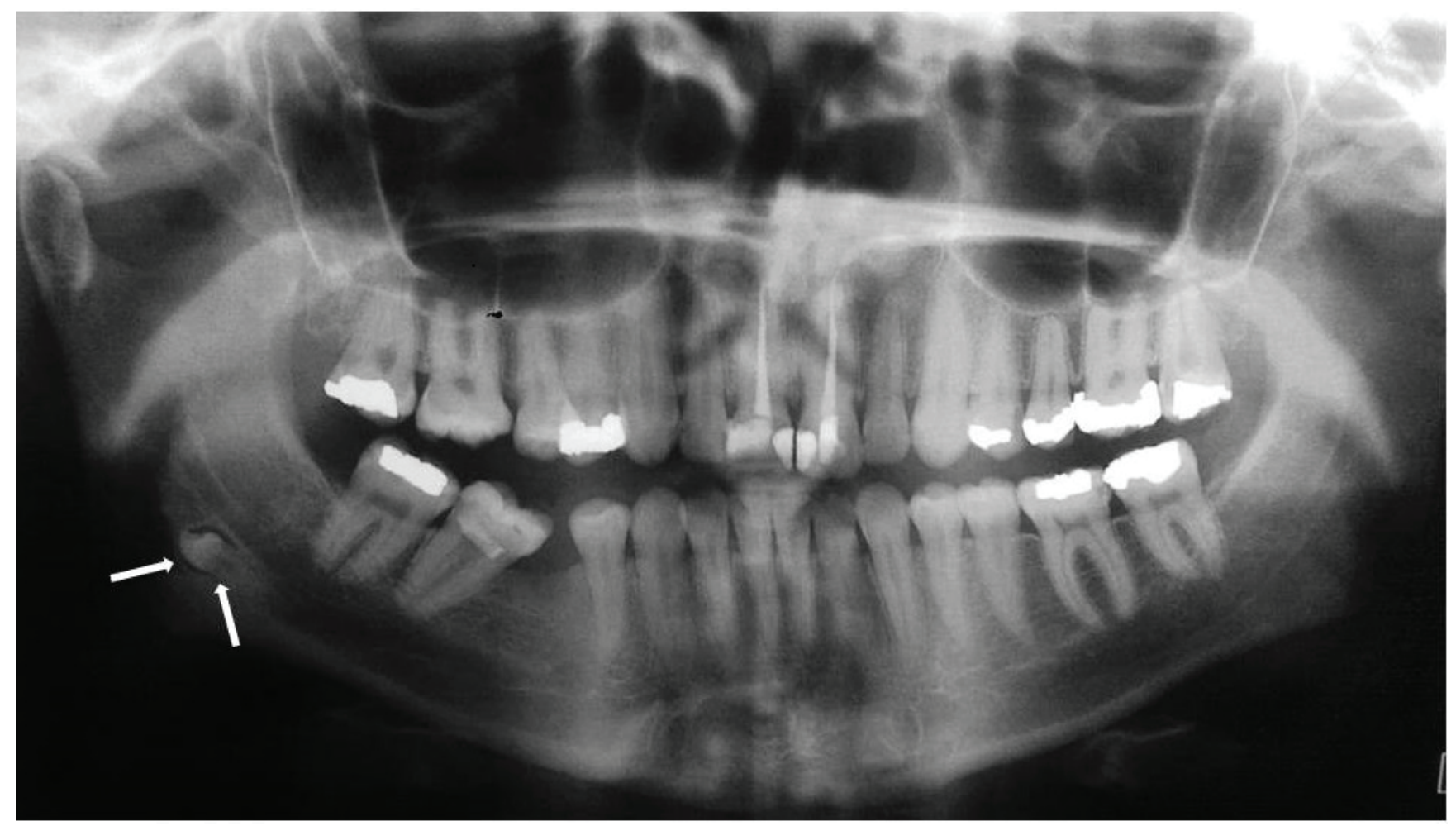

Fig. 1. Panoramic view shows distal migration of right second mandibular premolar below the inferior alveolar nerve canal 
prior to a dental examination. Therefore, surgical removal of the migrated tooth was not considered - the patient was asked to take periodic panoramic radiographs (twice a year) for early detection of any changes in size of dental pericoronal radiolucency due to the formation of cystic lesions, such as dentigerous or follicular cyst, and possible damages to the inferior alveolar canal.

\section{Discussion}

Intrabony migration of premolars has a low occurrence compared to other teeth. There are some etiological factors involved in the migration of teeth, such as retention or premature loss of a primary tooth, ectopic growth of tooth buds, genetic factors, endocrine disorders, and trauma. ${ }^{8}$ Distal migration is not yet completely understood, because the teeth tend to move mesially as a result of masticatory forces. ${ }^{3}$ Distal migration of MSP can occur due to the development of the tooth bud with a variable degree of distal inclination under the distal root of the primary second molar. When deciduous root is resorbed and the permanent molar is extracted early, the second premolar may migrate distally. In rare instances, the MSP was reported to migrate as far distally as the mandibular angle and the coronoid process. Such a migration is slow and occurs during a period of several years. ${ }^{5}$ The intrabony migration cannot be diagnosed by using routine periapical radiographs, because the tooth is usually horizontally under the root of other teeth and near the border of the mandible. ${ }^{5,7}$ Therefore, a radiographic examination including a panoramic view and sometimes occlusal radiographs should be requested. ${ }^{7}$ In accordance with our case, it is noted that premolar migration is more common in females. ${ }^{9,10}$ It was demonstrated that $55.5 \%$ of the mandibular ectopic premolars were located on the right side and $44.4 \%$ were on the left side as well. ${ }^{10}$ Intraosseous migration of MSP is often unilateral, horizontal and asymptomatic. It can appear at any age (ranging from 8 to 62 years old) and can happen mostly in adults older than 20 years of age, which corroborates our report. ${ }^{5,8,10}$ Treatment options for migrated premolars include surgical exposure combined with orthodontic therapy. If not treated, impacted teeth can lead to problems, e.g., carious lesions, infections, destruction of adjacent teeth, periodontal disease, and even oral and maxillofacial cysts or tumors. In 16\% of cases, cystic and neoplastic changes have been reported in relation to impacted teeth. ${ }^{11,12}$ On the other hand, complications associated with impacted tooth surgeries include: pain, swelling, trismus, bleeding, cellulitis, abscesses, septicemia, wound dehiscence, bone sequestra, paresthesia, anesthesia, hematoma, alveolar osteitis, temporomandibular joint dysfunction, and jaw fracture. ${ }^{13}$ In patients with no considerable sign or symptoms, a periodic radiographic observation should be suggested. ${ }^{5}$
In conclusion, taking a panoramic radiograph in patients with missing mandibular premolars should be considered, because in rare cases migration or transmigration of these teeth may happen.

\section{References}

1. Alves DB, Pedrosa EF, Andreo JC, de Carvalho IM, Rodrigues Ade C. Transmigration of mandibular second premolar in a patient with cleft lip and palate - Case report. J Appl Oral Sci. 2008;16:360-363.

2. Peck S. On the phenomenon of intraosseous migration of nonerupting teeth. Am J Orthod Dentofacial Orthop. 1998;113:515-517.

3. Shapira $Y$, Kuftinec MM. Intrabony migration of impacted teeth. Angle Orthod. 2003;73:738-743.

4. Nag R, Mathur R, Mathur J. Transmigration of unerupted mandibular second premolar associated with chronic nonspecific osteomylitis: Report of a rare case. Indian J Stomatol. 2014;5:31-32.

5. Matteson SR, Kantor ML, Proffit WR. Extreme distal migration of the mandibular second bicuspid. Angle Orthod. 1982;52:11-18.

6. Al-Ghurabi ZH. Prevalence of impacted premolar in Iraqi sample. IOSR J. 2014;13:16-20.

7. Shahoon $\mathrm{H}$, Esmaeili M. Bilateral intraosseous migration of mandibular second premolars in a patient with nine missing teeth. $J$ Dent (Tehran). 2010;7:50-53.

8. Fuziy A, Costa AL, Pastori CM, de Freitas FC, Torres FC, Pedrão LL. Sequential imaging of an impacted mandibular second premolar migrated from angle to condyle. J Oral Sci. 2014;56:303-306.

9. Infante-Cossio P, Hernandez-Guisado JM, Gutierrez-Perez JL. Removal of a premolar with extreme distal migration by sagittal osteotomy of the mandibular ramus: Report of case. J Oral Maxillofac Surg. 2000;58:575-577.

10. Kara MI, Ay S, Aktan AM, et al. Analysis of different type of transmigrant mandibular teeth. Med Oral Patol Oral Cir Bucal. 2011;16:e335-340.

11. Mortazavi $\mathrm{H}$, Baharvand M. Jaw lesions associated with impacted tooth: A radiographic diagnostic guide. Imaging Sci Dent. 2016;46:147-157.

12. Chu FCS, Li F, Lui VKB. Prevalence of impacted teeth and associated pathologies - A radiographic study of the Hong Kong Chinese population. Hong Kong Med J. 2003;9:158-163.

13. Anyanechi $C E$, Saheeb BD. The complications associated with the extraction of asymptomatic impacted mandibular third molars: A prospective clinical study of 63 patients. J Neurol Neurosci. 2016;7:98. 
